\title{
PENGARUH KOMPETENSI PEGAWAI TERHADAP KUALITAS PELAYANAN AKTA KELAHIRAN DI DINAS KEPENDUDUKAN DAN CATATAN SIPIL KABUPATEN BOGOR
}

\section{THE INFLUENCE OF EMPLOYEE COMPETENCY ON THE QUALITY OF BIRTHDAY SERVICES IN THE POPULATION DEPARTMENT AND CIVIL NOTICE OF BOGOR REGENCY}

\author{
O Subagja1a \\ 1Program Magister Administrasi Publik, Sekolah Pascasarjana,Universitas Djuanda Bogor, Indonesia \\ Jl. Tol Ciawi No. 1, Kotak Pos 35 Ciawi, Bogor 16720. \\ a Korespondensi:Oetje Subagja, E-mail: oetje.subagdja@unida.ac.id \\ (Diterima: 08-07-2019; Ditelaah: 09-07-2019; Disetujui: 14-09-2019)
}

\begin{abstract}
The purpose of this study to search for dominant factors that influence baby smoker 's behavior in Sukabumi. In 2017 Indonesia crowned as a baby smoker country. This is one of the shameful things for Indonesia. So that behavior must be pretended and decided. The method of this research is used to study cases with data collection techniques among interviewed, observed, and study documentation. The researcher used five respondents who have been interviewed for compared to some statements from those respondents. The result of this study is to find some factors which influence of baby smoker 's behavior among them environment factor which consists of family environment and society environment, religion, and education. The results of the analysis factors categorized and mapped dominant which influence. From the result of the analysis, we find that dominant factors which influence baby smoker 's behavior are family and social environment. But, the biggest factors are family which originated from parenting and family guidance when the child enters to imitating phase. The conclusion is the dominant factor's mapping which influences baby smoker 's behavior in Sukabumi influenced by parenting and family guidance which is not good. So, the child will imitate the behavior seen around it.
\end{abstract}

Keywords: Baby smoker, family environment, imitate phase, oral phase, social environment.

\begin{abstract}
ABSTRAK
Fenomena yang diangkat menjadi masalah penelitian adalah kualitas pelayanan Akta Kelahiran di Dinas Kependudukan dan Catatan Sipil Kabupaten Bogor dan korelasinya dengan masalah kompetensi pegawai. Metode penelitian yang digunakan adalah penelitian kuantitatif yang dilaksanakan dengan pendekatan penelitian survey sample. Pengambilan sampel dari populasi penelitian menggunakan stratified random sampling technique. Pengumpulan data menggunakan studi kepustakaan, kuesioner penelitian dan observasi. Analisis data menggunakan Analisis SEM (Structural Equation Model Analysis). Hasil Penelitian menunjukkan bahwa besarnya pengaruh Kompetensi Pegawai terhadap Kualitas Pelayanan Akta Kelahiran di Dinas Kependudukan dan Catatan Sipil Kabupaten
\end{abstract}


Bogor mencapai 0,543. Besarnya pengaruh kompetensi pegawai terhadap kualitas pelayanan akta kelahiran di Dinas Kependudukan dan Catatan Sipil Kabupaten Bogor ditentukan oleh motives, traits, self-concept, knowledge, and Skills. Konsep baru yang diperoleh dari analisis pengaruh Kompetensi Pegawai terhadap Kualitas Pelayanan Akta Kelahiran adalah tentang Keterampilan Pelayanan Administrasi Publik. Keterampilan pelayanan yang dimaksud meliputi keterampilan mengelola sumber daya administrasi yang terdiri atas sumber daya manusia, sumber daya anggaran, sumber daya kebijakan, dan sumber daya sarana pelayanan; keterampilan manajemen pelayanan yang terdiri atas perencanaan layanan, pelaksanaan pelayanan, pengendalian pelayanan, dan penilaian hasil pelayanan; keterampilan teknis pelayanan yang terdiri atas prosedur, tata cara dan waktu pelayanan; keterampilan sosial pelayanan.

Kata Kunci : Kompetensi, Kualitas Pelayanan Publik

Subagja, O. (2019). Pengaruh Kompetensi Pegawai Terhadap Kualitas Pelayanan Akta Kelahiran di Dinas Kependudukan dan Catatan Sipil Kabupaten Bogor. Jurnal Sosial Humaniora, 10(2), 67-74

\section{PENDAHULUAN}

Dukungan data kependudukan yang menyeluruh, akurat dan valid, selaras dengan perkembangan masyarakat merupakan salah satu kebutuhan administrasi kependudukan dan manajemen pemerintahan. Dukungan data kependudukan tersebut terutama sangat diperlukan dalam menyusun berbagai rencana kegiatan pelayanan publik dan pemberdayaan masyarakat. Karena itu fungsi data kependudukan yang menyeluruh, akurat dan valid menurut perkembangan masyarakat adalah salahsatu pendukung terselenggaranya berbagai kebijakan dan kegiatan pemerintah secara efektif dan efisien, sesuai dengan kondisi dinamis perkembangan masyarakat setempat.

Berangkat dari pemikiran yang demikian itu, kenyataan masih menunjukkan bahwa tidak semua daerah mempunyai data kependudukan yang menyeluruh, akurat dan valid. Kondisi data kependudukan yang demikian itu terjadi karena masih lemahnya pelaksanaan sistem administrasi kependudukan. Dengan kenyataan ini, maka fungsi data kependudukan yang menyeluruh, akurat dan valid tidak dapat diacuhkan begitu saja, karena mempunyai fungsi yang fundamental dalam merencanakan dan mengeksekusi berbagai kebijakan dan kegiatan public. Oleh sebab itu, pelayanan administrasi kependudukan yang berkualitas harus menjamin tersusunnya hasil pengolahan data kependudukan yang menyeluruh, akurat dan valid menurut dinamika perkembangan masyarakat menjadi sangat fundamental dalam penyelenggaraan sistem administrasi dan manajemen pemerintahan yang terkait erat dengan kepentingan publik. Lemahnya sistem pengolahan data kependudukan yang menyeluruh, akurat dan valid serta pelayanan administrasi kependudukan berkualitas yang belum prima tampak menjadi salah satu permasalahan administrasi pemerintahan yang cukup menonjol dalam penyelenggaraan sistem pemerintahan daerah. Dalam perspektif permasalahan data kependudukan ini, Kabupaten Bogor yang terbagi menjadi 13.595 RT, 3.497 RW, 427 Desa, 40 Kecamatan, dan berpenduduk mencapai 4.100.934 jiwa, masih menunjukkan sejumlah masalah data kependudukan yang belum menyeluruh, kurang akurat dan tidak valid. Kondisi data kependudukan yang demikian itu tentu dapat mempengaruhi proses perencanaan dan 
pelaksanaan berbagai program dan kegiatan pelayanan publik dan pemberdayaan masyarakat. Kondisi data kependudukan yang belum menyeluruh, kurang akurat dan tidak valid menurut kondisi dinamis perkembangan masyarakat juga menunjukkan bahwa pelayanan administrasi kependudukan yang berkualitas berlangsung di Kabupaten Bogor masih belum optimal. Kualitas pelayanan yang dimaksud adalah kinerja pelayanan public yang memberi kemudahan, kelancaran, dan bahkan memberi juga kepuasan kepada setiap masyarakat yang mengurusi kebutuhan administrasi kependudukan. Pelayanan administrasi kependudukan di Kabupaten Bogor diselenggarakan oleh Dinas Kependudukan dan Catatan Civil.

Belum secara optimal kualitas pelayanan mengenai Akta Kelahiran yang diselenggarakan oleh Dinas Kependudukan dan Catatan Sipil Kabupaten Bogor tampak menjadi suatu fenomena yang tidak berdiri sendiri. Artinya, terdapat sejumlah variabel yang mempengaruhi fenomena tersebut. Terhadap fenomena tersebut diasumsikan bahwa komunikasi dan kompetensi pegawai merupakan dua variabel yang berpengaruh signifikan terhadap kualitas servis Akta Kelahiran yang diselenggarakan oleh Dinas Kependudukan dan Catatan Sipil Kabupaten Bogor. Berdasarkan asumsi dipilih judul penelitian : "Pengaruh Kompetensi Pegawai Terhadap Kualitas Pelayanan Akta Kelahiran di Dinas Kependudukan dan Catatan Sipil Kabupaten Bogor".

\section{MATERI DAN METODE}

Ruben and Steward (1998:3) mendefinisikan bahwa Komunikasi merupakan proses penyampaian dan penerimaan informasi dari pihak penyelenggara atau petugas pelayanan akta kelahiran kepada pihak yang penerima layanan dan sebaliknya yang terungkap dari personal skills and attitudes, interpersonal skills, dan oral and written communication. Dari definisi tersebut maka dapat diperoleh tiga dimensi yaitu Dimensi interpersonal skills, Dimensi personal skills and attitudes, dan Dimensi oral and written communication. Ketiga dimensi dikembangkan menjadi 15 variabel. Spencer and Spencer (1993:9-11) mengatakan lima karakteristik kompetensi yang meliputi "Motives, Traits, Self-concept, Knowledge, dan Skill". Berdasarkan teori kompetensi ini disusun definisi konseptual variabel bahwa Kompetensi Pegawai adalah karakteristik kemampuan petugas dalam kegiatan servis akta kelahiran yang terungkap dari motives, traits, self-concept, knowledge and skills. Dari definisi ini diperoleh 5 dimensi kajian : Dimensi Motives, Dimensi Traits, Dimensi SelfConcept, Dimensi Knowledge dan Dimensi Skills. Lima dimensi dijabarkan menjadi 15 variabel manifes. Zeithaml et.al (1990:42) mengatakan "Servequal mengandung Tangibles; Reliability; Responsiveness; Assurance; dan Empathy. Berdasarkan teori kualitas pelayanan publik ini disusun definisi konseptual variabel bahwa Kualitas Pelayanan Akta lahir yang diselenggarakan oleh DISDUKCAPIL Kabupaten Bogor adalah karakteristik pelayanan public di bidang administrasi kependudukan yang terungkap dari tangible, reliability, responsiveness, assurance and empathy. Definisi konseptual ini dijabarkan menjadi 5 dimensi : Dimensi tangible, Dimensi reliability, Dimensi responsiveness, Dimensi assurance serta Dimensi emphaty. Lima dimensi tersebut dijabarkan lagi menjadi 15 variabel manifes.

\section{METODE PENELITIAN}

Penelitian menggunakan pendekatan penelitian kuantitatif. Populasi penelitian sebanyak 1.115 warga yang terdiri atas 358 warga dari 116 RW di 11 Desa/Kelurahan dalam wilayah Kecamatan Ciomas, 287 warga dari 73 RW di 13 Desa/Kelurahan dalam wilayah Kecamatan Ciawi, 215 
warga dari 50 RW di 9 Desa/Kelurahan dalam wilayah Kecamatan Parung, dan 255 warga dari 92 RW di 14 Desa/Kelurahan dalam wilayah Kecamatan Citeureup. Dengan jumlah populasi tersebut diambil sampel penelitian sebanyak 386 responden. Penentuan jumlah responden menggunakan simple random sampling technique. Teknik pengumpulan menggunakan Studi Kepustakaan untuk mengumpulkan data sekunder; Teknik Kuesioner untuk mengumpulkan data primer; dan Observasi. Teknik Analisis Data menggunakan SEM Analysis (Structural Equation Model Analysis).

\section{HASIL DAN PEMBAHASAN}

\section{Pengaruh Kompetensi terhadap Kualitas Pelayanan Akta Kelahiran :}

Besarnya pengaruh Kompetensi Pegawai terhadap Kualitas Pelayanan Akta Kelahiran mencapai 0,543. Besarnya pengaruh Kompetensi Pegawai terhadap Kualitas Pelayanan Akta Kelahiran ditentukan oleh keeratan hubungan motives, traits, self-concept, knowledge and skills. Untuk mengetahui signifikansi pengaruh variabel laten eksogen Kompetensi Pegawai terhadap variabel Kualitas Pelayanan Akta Kelahiran, dilakukan pengujian hipotesis dengan statistik uji t student. Pengujian hipotesis bertujuan untuk mengetahui apakah terbukti bahwa secara populasi variabel laten eksogen Kompetensi Pegawai berpengaruh signifikan terhadap variabel laten endogen Kualitas Pelayanan Akta Kelahiran. Hasil pengujian $\mathrm{t}$ student menunjukkan bahwa nilai $t$ hitung lebih besar daripada nilai $t$ tabel. Kriteria hasil pengujian $t$ student adalah bahwa Kompetensi Pegawai berpengaruh secara signifikan terhadap Kualitas Pelayanan Akta Kelahiran. Hasil pengujian ini bermakna bahwa apabila kompetensi pegawai ditingkatkan atau meningkat, maka secara stimulan peningkatan tersebut diikuti dengan peningkatan Kualitas Pelayanan Akta Kelahiran. Peningkatan yang demikian itu dapat terjadi karena di antara kompetensi pegawai dengan Kualitas Pelayanan Akta Kelahiran terjalin suatu dinamika hubungan kausal. Artinya, kompetensi pegawai dalam pelaksanaan kebijakan dan kegiatan pelayanan merupakan faktor penyebab belum optimalnya kualitas pelayanan akta kelahiran. Oleh sebab itu, Kualitas Pelayanan Akta Lahir yang diselenggarakan oleh DISDUKCAPIL Kabupaten Bogor dapat ditingkatkan dengan meningkatkan, memperbaiki, mengoptimalkan 15 indikator kompetensi pegawai. Lima belas indikator kompetensi pegawai yang dimaksud adalah Dorongan kebutuhan ekonomi; Dorongan kebutuhan sosial; (3) Dorongan kebutuhan psikologis; (4) Watak; (5) Sifat; (6) Sikap; (7) Penampilan; (8) Tutur bahasa; (9) Perilaku; (10) Pengetahuan mengenai prosedur pelayanan; (11) Pengetahuan mengenai teknis pelayanan; (12) Keterampilan Administratif; (13) Keterampilan Manajerial; Keterampilan Teknis; serta (15) Social Skills.

Dari interpretasi data distribusi skor jawaban para responden penelitian terhadap setiap indikator yang tercakup dalam operasionalisasi variabel kompetensi aparatur birokrasi teridentifikasi hal-hal sebagai berikut : Pertama, motif yang mendorong petugas pelayanan melakukan atau tidak melaksanakan sesuatu (motives) yang mencerminkan kompetensi pegawai dalam melaksanakan kebijakan dan kegiatan pelayanan mendukung peningkatan kualitas pelayanan. Konsep motif yang mempengaruhi kinerja petugas pelayanan ini meliputi dorongan kebutuhan ekonomi, dorongan akan kebutuhan sosialnya, dan dorongan kebutuhan psikologis. Dengan demikian motives petugas pelayanan yang tercermin dari kompetensi pegawai 
meningkatkan kualitas pelayanan. Kedua, watak dan kebiasaan petugas dalam melakukan pekerjaannya (traits) yang mencerminkan kompetensi pegawai dalam melaksanakan kebijakan dan kegiatan pelayanan mendukung peningkatan kualitas pelayanan. Ciri watak dan kebiasaan yang mempengaruhi kinerja petugas pelayanan ini meliputi watak, sifat dan sikap dalam bekerja. Dengan demikian traits petugas pelayanan yang tercermin dari kompetensi pegawai meningkatkan kualitas pelayanan.

Ketiga, pencitraan diri petugas dalam melakukan pekerjaannya (self-concept) yang mencerminkan kompetensi pegawai dalam melaksanakan kebijakan dan kegiatan pelayanan mendukung peningkatan kualitas pelayanan. Ciri pencitraan diri yang mempengaruhi kinerja petugas pelayanan ini meliputi penampilan diri, tutur bahasa \& perilaku petugas didalam bekerja. Dengan demikian self-concept petugas pelayanan yang tercermin dari kompetensi pegawai meningkatkan kualitas pelayanan.

Keempat, pengetahuan pelaksana pelayanan di dalam melaksanakan pekerjaan (knowledge) yang mencerminkan kompetensi pegawai dalam melaksanakan kebijakan dan kegiatan pelayanan mendukung peningkatan kualitas pelayanan. Konsep pengetahuan yang mempengaruhi kinerja petugas pelayanan ini meliputi pengetahuan mengenai teknis pelayanan dan pengetahuan mengenai prosedur pelayanan. Dengan demikian knowledge petugas pelayanan yang tercermin dari kompetensi pegawai meningkatkan kualitas pelayanan.

Kelima, keterampilan petugas pelayanan di dalam melakukan pekerjaannya (skills) yang mencerminkan kompetensi pegawai dalam melaksanakan kebijakan dan kegiatan pelayanan mendukung peningkatan kualitas pelayanan. Konsep keterampilan yang mempengaruhi kinerja petugas pelayanan ini meliputi keterampilan administratif, keterampilan manajerial, keterampilan teknis, dan keterampilan sosial. Dengan demikian skills petugas pelayanan yang tercermin dari kompetensi pegawai meningkatkan kualitas pelayanan.

Kompetensi merupakan kondisi dinamis SDM yang dipandang dan dinilai menurut persoalan-persoalan keorganisasian dan persoalan-persoalan pekerjaan dalam organisasi. Karena itu deskripsi kompetensi terkait erat dengan peran SDM dalam organisasi. Eksistensi suatu organisasi, terutama organisasi yang berkaitan dengan urusan administrasi publik, jelas tidak lepas dari perubahan lingkungan strategis. Perubahan lingkungan strategis ini tidak hanya terjadi dalam dimensi lokal, dimensi nasional, tetapi terjadi juga dalam dimensi global. Perubahan lingkungan strategis merupakan salah satu dampak dari deras kemajuan informasi dan teknologi komunikasi yang semakin mengglobal. Dalam dimensi pandangan seperti itu, menurut Datton \& Jackson (dalam Setyawan, 2002:3), suatu organisasi harus mampu menyusun strategi dan kebijakan ampuh untuk mengatasi setiap perubahan yang terjadi. Salah satu bidang fungsional strategi yang menjadi perhatian adalah MSDM. Karena itu, setiap organisasi perlu mengembangkan suatu sistem MSDM yang dapat diarahkan dan didayagunakan untuk menyikapi secara kritis dan cermat setiap perubahan yang berpengaruh terhadap eksistensi organisasi.

Evans dan Naiper (dalam Setyawan, 2002:19) mengatakan bahwa peran strategis sumber daya manusia sebagai outcome proses repositioning dapat memberikan kontribusi signifikan dalam perencanaan strategis bisnis. Upaya repositioning peran sumber daya manusia memiliki beberapa manfaat seperti adanya pengakuan bahwa peran divisi sumber daya manusia ini penting dan strategis bagi organisasi karena terkait dengan kegiatan manajemen kepemimpinan dan komunikasi organisasi. Implikasi repositioning peran sumber daya manusia 
akan membuat suatu organisasi perlu melakukan pengembangan nilai-nilai budaya organisasi dengan lebih meningkatkan berbagai kompetensi sumber daya manusia di samping merubah perilaku sumber daya manusia agar menjadi lebih produktif. Karena itu, pengembangan sumber daya manusia, menurut Siagian (1998:40) sebagai potensi yang merupakan aset dan berfungsi sebagai modal (non material/non finansial) di dalam organisasi bisnis yang dapat diwujudkan menjadi potensi nyata (real) secara fisik dan non fisik, perlu diarahkan untuk menyikapi berbagai tantangan manajemen sumber daya manusia. Dalam konteks tantangan yang dimaksud, Siagian (1998:26) mengemukakan bahwa kebijaksanaan apapun yang dirumuskan dan ditetapkan di bidang sumber daya manusia dan langkah-langkah apapun yang diambil dalam manajemen sumber daya manusia itu, semuanya harus berkaitan dengan pencapaian berbagai jenis tujuan yang telah ditetapkan untuk dicapai. Pada dasarnya berbagai tujuan tersebut dapat dikategorikan pada empat jenis, yaitu tujuan masyarakat sebagai keseluruhan; tujuan organisasi yang bersangkutan; tujuan fungsional dalam arti tujuan Manajemen Sumber daya manusia di dalam suatu organisasi; dan tujuan pribadi para anggota organisasi.

Dengan pendapat Siagian itu, maka peran sumber daya manusia dalam birokrasi pemerintahan menjadi sangat penting dan bernilai strategis. Karena itu perlu dikembangkan suatu kebijakan MSDM atau manajemen kepegawaian yang tidak hanya terarah agar bisa mencapai tujuan sebuah organisasi dan tujuan individu, tetapi yang terpenting terarah juga untuk melayani kepentingan masyarakat. Dalam konteks inilah, kompetensi aparatur birokrasi sebagai suatu konsep sumber daya manusia menjadi sangat penting agar meningkatkan pelayanan yang berkualitas kepada masyarakat.
Dari narasi Spencer \& Spencer di atas didapatkan suatu konsep kepahaman bahwa "underlying characteristics" mengandung arti kompetensi merupakan bagian terdalam kepribadian yang melekat pada seseorang yang dapat memprediksi berbagai keadaan, tugas dan pekerjaan. Sebuah kata "causally related" bisa diterjemahkan bahwa kompetensi merupakan sesuatu yang berkorelasi dengan kinerja dan perilaku. Di dalam kontekstual, Spencer and Spencer (1993:9-11) mendeskripsikan lima karakteristik kompetensi berikut : (1) Motives. The thing a person constantly thinks about or wants that cause action. Motives "drive, direct, and select" behavior toward certain action or goals and away from others. (2) Traits. Physical characteristics and consistent responses to situation of information. (3) Self-concept. A person's attitude, values, or self-image. (4) Knowledge. Information a person has in specific content areas. (5) Skill. The ability to perform a contain physical or mental task

Dari pendapat Spencer \& Spencer itu diketahui bahwa "motives" merupakan dorongan sesuatu di mana seseorang secara konsisten berfikir sehingga ia melakukan suatu tindakan. Motif ini bersifat dinamis, dan saling bergantian antara satu motif dengan motif lainnya, dan prosesnya menekan seseorang untuk bersikap dan bertindak menurut cara tertentu untuk memenuhi motif tersebut. Penilaian terhadap motivasi seseorang dalam bekerja merupakan hal penting untuk memahami kompetensi seseorang. Mengacu pada hal traits, Spencer and Spencer (1993) menyebutkan "traits" merupakan physical characteristic and information or consistent response to situations. Dengan demikian "traits" adalah watak yang mencirikan seseorang dalam berperilaku atau katakanlah bagaimana seseorang itu menanggapi sesuatu dengan metode tertentu di lingkungan kerjanya. Dari pendapat 
Spencer and Spencer ini terungkap bahwa "traits" memprediksikan apa yang orang lakukan pada pekerjaan mereka untuk waktu lama. Karena traits adalah karakteristik atau sifat bawaan seseorang, maka dengan sendirinya trait merupakan faktor internal seseorang yang menunjukkan kapasitas dirinya dalam bekerja. Sementara itu, dalam hal selfconcept, Spencer and Spencer (1993:10) menyebutkan bahwa self-concept adalah a person's attitude, values or self image. Spencer and Spencer memberi contoh bahwa "Self-confidence, a person has belief that he or he can be effective in almost any situation's part of that person is concept of self". Dengan demikian "self concept" adalah nilai-nilai dan sikap yang dianut seseorang dalam mengaktualisasikan peran dirinya di lingkungan kerjanya dengan memanfaatkan knowledge dan skills yang dimilikinya. Disadari atau tidak disadari self concept membentuk suatu pencitraan diri seseorang di tengah lingkungan kerja. Sebagai misal, seseorang yang diangkat menjadi manajer, disadari atau tidak disadari ia akan segera mengembangkan sikap kerja dan komunikasi sosialnya dengan gaya kerja yang sesuai dengan kedudukannya sebagai seorang manajer. Misal lain, seseorang yang mempunyai traits yang senang akan pujian cenderung menampilkan dirinya berbeda dengan penampilan orang-orang di sekitarnya agar selalu menarik perhatian orang lain. Penampilan yang demikian itu merupakan pencitraan diri. Begitu juga orang yang jujur akan selalu berupaya untuk berlaku jujur, karena kejujuran dianggap sebagai citra dirinya. Jadi, self concept merupakan pencitraan diri seseorang dalam bekerja. Semakin tinggi jabatan seseorang maka dengan sendirinya aktualisasi self concept pun semakin tinggi. Self concept ini terkait dengan kebutuhan aktualisasi diri seseorang di dalam mengeksistensikan dirinya sendiri di tengah suatu lingkungan, dan aktualisasi diri itu jelas bergantung pada kapasitas "knowledge" yang dimilikinya. Di dalam kontekstual ini, Spencer dan Spencer (1993:10) menyebutkan bahwa "knowledge" merupakan information a person has in specific content areas. Dengan demikian knowledge adalah informasi atau pengetahuan yang dimiliki seseorang. Pengetahuan adalah kemampuan yang kompleks, sebab setiap orang memiliki pengetahuan- pengetahuan yang dinamis. Sebagai misal, pengetahuan seseorang yang mendalam tentang penguasaan teknologi informasi dapat menumbuhkan keterampilan orang tersebut dalam menggunakan teknologi komputer. Kinerja seseorang yang memiliki skills dengan kinerja orang yang tidak mempunyai skills tentu sangat berbeda. Dalam hal skills ini, Shermon (2004:29) mengatakan "The ability to perform certain mental or physical tasks, consistently, accurately and when displayed in meaningful ways and behaviorally turns into a competency." Dengan demikian "skills" pada dasarnya adalah keterampilan seseorang untuk melaksanakan suatu tugas atau pekerjaan baik itu secara fisik ataupun mental. Skills bisa juga disebut sebagai keahlian teknis seseorang dalam melaksanakan prosedur dan tata cara kerja menurut ukuran tertentu, seperti misalnya melakukan pekerjaan secara produktif, efektif atau efisien. Skills mensinergikan fungsi kecerdasan intelektual dan fungsi kemampuan fisik. Dalam konteks ini, skills merupakan manifestasi kemahiran dalam melaksanakan teknis pekerjaan yang menuntut keterampilan fisik tertentu. Skills juga terkait dengan wawasan pengalaman kerja seseorang. Semakin berpengalaman seseorang dalam menyelesaikan suatu teknis pekerjaan, maka dengan sendirinya keterampilan kerja orang tersebut semakin terasah. Sebagai misal, skills seorang petugas pelayanan yang berpengalaman dalam memberi pelayanan kesehatan pada masyarakat sekitar, tentu berbeda dengan seorang petugas yang belum berpengalaman. Artinya, skills dapat sekaligus menunjukkan bagaimana kapasitas pengetahuan kerja, kemahiran 
kerja dan pengalaman kerja seseorang. Karena itu skills dapat meningkatkan kualitas pelayanan.

\section{KESIMPULAN}

Dari pembahasan hasil penelitian yang diolah dengan metode Analisis SEM diperoleh kesimpulan sebagai berikut : Kompetensi pegawai berpengaruh terhadap kualitas pelayanan akta kelahiran di Dinas Kependudukan dan Catatan Sipil Kabupaten Bogor. Besarnya pengaruh variabel kompetensi pegawai terhadap variabel kualitas sebuah pelayanan akta kelahiran di DISDUKCAPIL Kabupaten Bogor ditentukan oleh motives, traits, selfconcept, knowledge, and Skills. Adanya pengaruh tersebut menunjukkan bahwa di antara kompetensi pegawai dengan pelayanan mengenai akta kelahiran yang berkualitas terjalin hubungan kausalitas yang bermakna bahwa apabila kompetensi staf ditingkatkan atau meningkat maka secara stimulan peningkatan tersebut diikuti dengan peningkatan kualitas pelayanan akta kelahiran. Stimulasi peningkatan yang demikian itu lebih banyak distimulasi oleh Skills.

Konsep baru yang diperoleh dari pengolahan hasil penelitian adalah keterampilan petugas pelayanan meningkatkan kualitas pelayanan publik. Keterampilan petugas pelayanan yang dimaksud meliputi keterampilan mengelola sumber daya administrasi pelayanan yang terdiri atas sumber daya manusia, sumber daya anggaran, sumber daya kebijakan, dan sumber daya sarana pelayanan; keterampilan menerapkan manajemen pelayanan yaitu perencanaan layanan, pelaksanaan pelayanan, pengendalian pelayanan, dan penilaian hasil pelayanan; keterampilan melaksanakan teknis pelayanan yang terdiri atas pelaksanaan prosedur, tata cara dan waktu pelayanan; dan keterampilan sosial petugas pelayanan dalam melayani pihak penerima layanan.

\section{DAFTAR PUSTAKA}

Nawawi, Hadari. 1994. Manajemen Sumber Daya Manusia. Yogyakarta : Gadjah Mada University Press.

Pace, Wayne, R and Faules, F, Don. 2006.

Komunikasi Organisasi Strategi

Meningkatkan Kinerja Perusahaan. PT

Rosdakarya.

Ruben, Brent. D and Steward, Lea, P. 1998. Communication and Human Behavior Fourth Edition. Sutarto. 1991. Dasardasar Komunikasi Administrasi. Duta Wacana University Press.

Shermon, Ganesh. 2004. Competency based HRM. India : Tata McGraw-Hill Publishing Company Limited.

Spencer, Lyle, M. Jr. And Spencer, M. Signe. 1993. Competencies At Work Models For Superior Performance, United State of America: John Wiley \& Sons, Inc.

Zeithaml, Valarie. A Parasuraman, L, Leonard A. Berry. 1990. Delivering Quality Service : Balancing Customer Perception and Expectation. New York. The Free Press Advision of Mac Millan Inc. 